\title{
Analisis Kinerja Rantai Pasok PT SUJ MEDAN
}

\author{
Faiz Ahmad Sibuea ${ }^{1 *}$ \\ Rita Nurmalina ${ }^{2}$ \\ Amzul Rifin ${ }^{3}$ \\ 1), 2), 3)Program Studi Agribisnis, Institut Pertanian Bogor,Indonesia \\ *email: faizahmadsibuea@gmail.com \\ Diterima: Februari 2020 Disetujui: April 2020 Dipublish: April 2020
}

\begin{abstract}
Abstrak
Industri perunggasan khususnya ayam broiler pedaging merupakan basis ekonomi rakyat yang berpotensi tinggi dalam meningkatkan pertumbuhan ekonomi yang inklusif (inclusive economy growth). Selain itu, juga dapat dikaji dari sisi distribusi produk, dari titik produsen hingga ke konsumen akhir. Salah satu perusahaan yang bergerak di bidang produksi ayam broiler pedaging adalah PT SUJ. Tujuan penelitian ini menganalisis kinerja supply chain peternak dan perusahaan dengan menggunakan pendekatan model Supply Chain Operational Reference (SCOR) dengan memperhatikan atribut internal dan eksternal. Hasil penelitian menunjukkan bahwa PT SUJ memiliki empat lembaga yang terlibat dalam pemasaran ayam broiler yaitu peternak mitra, perusahaan, Broker/agen dan konsumen. Untuk pengukuran kinerja supply chain, Hasil pengukuran kinerja rantai pasok ayam broiler pedaging di tingkat peternak mitra pada atribut responsiveness dan fleksibility telah mencapai posisi kinerja terbaik (superior). Namun, untuk atribut reliability dan aset masih berada di level advantage. Sementara itu, nilai kinerja rantai pasok ayam untuk tingkat perusahaan broiler pada atribut reliability, responsivness dan flexibilty sudah mencapai kinerja terbaik (superior). Namun, untuk atribut aset perusahaan hanya mencapai posisi baik (advantage). Secara umum kinerja rantai pasok ayam broiler sudah baik di tingkat peternak maupun perusahaan.
\end{abstract}

Kata Kunci : Kinerja, Ayam Broiler, SCOR

\begin{abstract}
The poultry industry, especially broilers is the basis of the people's economy which has high potential in increasing inclusive economic growth. In addition, it can also be studied from the product distribution side, from the point of producer to the end consumer. One of the companies engaged in the production of broiler broilers is PT SUJ. The purpose of this study is to analyze the performance of farmer and company supply chains using the Supply Chain Operational Reference (SCOR) model approach with regard to internal and external attributes. The results showed that PT SUJ has four institutions involved in marketing broiler chickens, namely breeder partners, companies, brokers / agents and consumers. For measuring supply chain performance, the results of measuring the performance of broiler broiler supply chains at the level of partner farmers on the attributes of responsiveness and flexibility have achieved the best performance position (superior). However, for the attributes of reliability and assets are still at the level of advantage. Meanwhile, the value of chicken supply chain performance for the broiler company level on the attributes of reliability, responsiveness and flexibilty has achieved the best performance (superior). However, for attributes the company's assets only achieve a good position (advantage). Generally, the performance of broiler chicken supply chains is good at the farmer and company level.
\end{abstract}

Keywords : Performance, Broiler Chicken, SCOR.

\section{LATAR BELAKANG}

Industri perunggasan adalah industri berbasis ekonom rakyat yang dapat meningkatkan pertumbuhan ekonomi yang inklusif (inclusive economy growth) jika dilakukan dengan 
pendekatan secara terpadu. Secara khusus untuk ayam broiler, perkembangan dan pertumbuhan ayam jenis broiler ini dapat dilihat dari dua sisi, yaitu sisi penawaran atau pasokan (supply side) dan permintaan atau konsumsi (demand side). Ayam broiler adalah ayam hasil budidaya teknologi. Ayam broiler adalah jenis ayam yang mengalami pertumbuhan yang cepat, dagingnya lebih banyak, pakan irit dan usia panen ayam yang lebih cepat yaitu 21 hari hingga 35 hari.

Salah satu perusahaan yang bergerak di bidang produksi ayam ras pedaging adalah PT SUJ. PT SUJ merupakan perusahaan yang bergerak di bidang peternakan dan merupakan anak perusahaan PT. Cheil Jedang Feed. Pada 1997 PT Cheil Jedang Indonesia yang bergerak dalam industri pakan ternak ayam yang diproduksi menggunakan merk Superfeed, mendirikan PT SUJ. PT SUJ melakukan ekspansi dengan membangun beberapa unit peternakan ayam di beberapa lokasi pabrik yang tersebar di wilayah Pulau Sumatera seperti (Aceh, Medan, Padang, Jambi dan Palembang), Jawa (Surabaya) dan Kalimantan (Palangkaraya). Namun, untuk wilayah Medan sendiri PT SUJ baru membuka ekspansinya dalam jangka waktu satu tahun.

Kesuksesan sebuah perusahaan tergantung pada bagaimana efektivitas rantai pasok yang digunakan. Sistem pengukuran kinerja diperlukan sebagai pendekatan dalam rangka mengoptimalisasikan efisiensi jaringan rantai pasok. Tujuan utama dalam pengukuran ini adalah untuk mendukung perancangan pasar, evaluasi kinerja, dan menentukan langkahlangkah ke depan mengenai strategi, taktik, dan operasional (Tsao, 2013).

Namun, ada beberapa kendala pemasaran yang terjadi dalam perusahaan SUJ. Persoalan yang terjadi adalah masalah persediaan. Jadi, ketika permintaan yang berasal dari broker berjumlah besar perusahaan masih belum mampu menyediakan ayam broiler pedaging sesuai dengan yang diinginkan broker.

PT SUJ selalu berusaha mengutamakan pemenuhan kebutuhan broker atau pedagang besar, namun permasalahannya banyak pasokan peternak yang tidak sesuai dengan standar sehingga tidak bisa dikirim ke broker Oleh karena itu, penelitian mengenai kinerja perusahaan perlu dilakukan. Berdasarkan uraian diatas perlu dikaji dan dianalisis bagaimana kinerja rantai pasok ayam broiler di PT SUJ.

\section{METODE PENELITIAN}

Penelitian dilakukan di PT SUJ di daerah Kota Binjai, Mencirim dan Tanjung Langkat yang terdiri dari tiga pabrik peternakan yaitu Pabrik Berseri Farm, Pabrik Farm Berjaya, Pabrik Farm Kebagusan dan Pabrik Farm Berkah Provinsi SumateraUtara.

Jenis data yang digunakan dalam penelitian adalah data primer. Data primer yang dikumpulkan berupa kinerja supply chain yang terdiri dari jumlah permintaan dan jumlah pengiriman ayam broiler pedaging ke pedagang besar selama 4 bulan dari Juni - September 2019 di setiap lembaga pemasaran yang terlibat. Peternak mitra 
yang dijadikan responden sebanyak 24 peternak yang secara rutin mengirimkan ayam dan 11 orang agen besar yang mengambil ayam ke perusahaan.

Metode analisis yang digunakan yaitu analisis kuantitatif penggunaan indikator-indikator untuk metode Supply Chain Operation Refference (SCOR). Pengukuran kinerja supply chain menggunakan metode Supply Chain Operational Reference (SCOR) yang terdiri dari dua atribut kinerja yaitu internal (sebagai monitoring kemampuan internal) dan eksternal (berhubungan dengan pelanggan). Analisis kinerja rantai pasok secara kualitatif perlu didukung adanya ukuran kinerja yang kuantitatif agar menghasilkan hasil kinerja yang lebih terukur dan objektif. Keberhasilan rantai pasok dapat dilihat dari tingkat kinerja yang dimilikinya. Pengukuran suatu kinerja rantai pasok dapat dilakukan dengan metode Supply Chain Operational Reference (SCOR). Dalam penelitian dengen metode SCOR untuk pertanian, rata-rata hasil penelitian selalu menunjukkan kinerja yang relatif baik dikarenakan produk pertanian yang bersifat mudah rusak maka produk tersebut harus cepat disampaikan ke tangan konsumen. Hal ini sejalan dengan hasil penlitian Saputra dan Fithri (2012), Mutakin dan Hubeis (2011) dan Anggraeni (2012) yang menggunakan metode SCOR untuk pengukuran rantai pasok pertanian.

Tabel 1. Benchmarking Supply chain

\begin{tabular}{|c|c|c|c|c|}
\hline \multirow[t]{2}{*}{ Atribut } & \multirow[t]{2}{*}{ Indikator } & \multicolumn{3}{|c|}{ Benchmark } \\
\hline & & Parity & Advantage & Superior \\
\hline \multicolumn{5}{|c|}{ Kinerja Eksternal } \\
\hline \multirow[t]{3}{*}{ Reliabilitas } & Kinerja Pengiriman(\%) & $85.00-89.00$ & $90.00-94.00$ & $\geq 95.00$ \\
\hline & Kesesuaian standar (\%) & $80.00-84.00$ & $85.00-89.00$ & $\geq 90.00$ \\
\hline & Pemenuhan Pesanan (\%) & $94.00-95.00$ & $96.00-97.00$ & $\geq 98.00$ \\
\hline \multirow[t]{2}{*}{ Responsivitas } & $\begin{array}{l}\text { Siklus pemenuhan pesanan } \\
\text { (hari) }\end{array}$ & $8.00-7.00$ & $6.00-5.00$ & $\leq 4.00$ \\
\hline & Lead Time (hari) & $7.00-6.00$ & $5.00-4.00$ & $\leq 3.00$ \\
\hline Fleksibilitas & $\begin{array}{l}\text { Fleksibilitas supply chain } \\
\text { (hari) }\end{array}$ & $42.00-27.00$ & $26.00-11.00$ & $\leq 10.00$ \\
\hline \multicolumn{5}{|c|}{ Kinerja Internal } \\
\hline \multirow[t]{2}{*}{ Asset } & Cash to Cash Cycle Time & $45.00-34.00$ & $33.00-21.00$ & $\leq 20.00$ \\
\hline & Persediaan Harian & $27.00-14.00$ & $13.00-0.01$ & $=0.00$ \\
\hline Cost & $\begin{array}{l}\text { Total Supply chain } \\
\text { Management Cost (Rp) }\end{array}$ & $13.00-9.00$ & $8.00-4.00$ & $\leq 3.00$ \\
\hline
\end{tabular}

Sumber: Bolstorff dan Rosenbaum (2011)

Adapun atribut kinerja eksternal antara lain reliability/agility, fleksibility, dan responsiveness sedangkan atribut kinerja internal adalah cost dan asset. Reliability adalah kemampuan untuk melaksanakan pekerjaan sesuai yang diharapkan, antara lain: tepat waktu, kualitas sesuai standar yang diminta, dan tepat jumlah. Responsiveness adalah kecepatan dalam melaksanakan pekerjaan yang diukur 
dengan siklus serta lead time. Agility/flexibility adalah kemampuan untuk merespons perubahan eksternal kompetitif di pasar. Cost merupakan biaya untuk menjalankan proses-proses rantai pasok. Sedangkan asset adalah kemampuan untuk memanfaatkan aset secara produktif. Setelah masing-masing matrik kinerja supply chain diukur dan dihitung, nilai-nilai yang dihasilkan dibandingkan dengan nilai Superior SCOR card, sebagai nilai benchmark penelitian ini. Kualifikasi nilai kinerjadi setiap atribut terdiri dari tiga level yaitu parity, advantage dan superior. Kinerja supply chain yang diukur meliputi kinerja petani mitra dan kinerja PT SUJ. Dimana benchmarking yang ada dalam kinerja SCOR disajikan dalam tabel 1.

\section{HASIL DAN PEMBAHASAN Kinerja Supply Chain}

\section{A. Kinerja Peternak Mitra}

\section{- Pengukuran Kinerja Eksternal}

\section{Kinerja Pengiriman}

Kinerja pengiriman adalah ukuran pengiriman kebutuhan ayam yang diminta broker secara tepat waktu. Berdasarkan data, nilai dari indikator kinerja pengiriman untuk setiap peternak mitra bernilai sama yaitu $100 \%$. Seluruh peternak mitra ayam telah mendistribusikan pesanan tepat waktu. Hal ini berarti sudah sesuai dengan penelitian Sari (2015) yang meneliti kinerja ayam broiler di Bandung dengan hasil penelitian bahwa indikator kinerja pengiriman untuk ayam broiler telah mencapai
100 persen. Apabila pesanan yang diminta yang tepat waktu 100 persen berarti kinerja supply chain mencapai sempurna Hal ini bisa tercapai karena setiap hari asisten ternak perusahaan terus mengawasi perkembangan budidaya ayam

\section{Pemenuhan Pesanan}

Pemenuhan pesanan adalah jumlah permintaan keseluruhan yang dapat dipenuhi tanpa menunggu dan dinyatakan dalam persen. Berdasarkan tabel 2, dapat diketahu bahwa keseluruhan peternak mitra telah mencapai nilai 100 persen untuk indikator pemenuhan pesanan. Hal ini sejalan juga dengan penelitian Paul (2014) yang meneliti tentang rantai pasok untuk peternakan dan dapat disimpulkan bahwa kinerja pemenuhan pesanan telah terkondisikan dengan baik. Kondisi dapat tercapai karena koordinasi yang terjalin dengan baik antara perusahaan dan juga peternak mitra.

\section{Kesesuaian dengan Standar}

Kesesuaian standar adalah perbandingan antara jumlah permintaan konsumen yang memenuhi standar dan seluruh permintaan konsumen yang dinyatakan dalam persen. Dalam tabel 2, kesesuaian standar pesanan supply chain pada periode juni sebesar 90,25 \%, bulan Juli 92,2 \%, bulan Agustus menjadi 92,19 \% dan 93,01\% untuk bulan September dengan ratarata dalam 4 bulan tersebut adalah 91,9\%. rata-rata kesesuain standar pesanan untuk setiap bulan menunjukkan siklus yang stabil Nilai 
kesesuaian standar dari bulan ke bulan menunjukkan rata-rata $91,9 \%$ artinya ada sekitar $8,1 \%$ per bulan yang tidak mencapai standar. Nilai 91,9 \% juga menunjukkan bahwa kinerja peternak untuk kesesuaian standar produk masih berada dalam posisi advantage. Hal tersebut sesuai dengan benchmarking scorCard yang menyebutkan jika nilai indikator diatas $90 \%$ maka sudah mencapai level superior.

\section{Lead Time Pemenuhan Pesanan}

Lead time yang diukur adalah waktu yang menunjukkan lamanya peternak memenuhi kebutuhan perusahaan. Berdasarkan tabel 2, lead time rantai pasok pada periode Juni sebesar 0,684 hari (16,416 jam) kemudian di bulan Juli menjadi 0,6834 hari (16,4016 jam), bulan Agustus 0,660 hari $(15,84$ jam) dan 0,687 hari $(16,48$ jam) untuk bulan September dengan rata-rata dalam 4 bulan tersebut adalah 0.679 hari $(16,29 \mathrm{jam})$. Nilai lead time tersebut selalu menunjukkan kinerja lead time kurang dari 3 hari yang berarti bahwa indikator lead time telah berada dalam level superior dimana dalam benchmark scorCard level tersebut telah mencapai kinerja terbaik (Bolstorff dan Rosenbaum 2011).

\section{Siklus Pemenuhan Pesanan}

Siklus pemenuhan pemesanan adalah kondisi dimana keseluruhan waktu yang diperlukan peternak pada satu siklus order. Berdasarkan rekapitulasi perhitungan, Dalam tabel 2 , siklus pemenuhan pesanan supply chain pada periode Juni sebesar 0,434 hari (10,4 jam) kemudian di bulan Juli menjadi 0,433 hari $(10,39$ jam), bulan Agustus 0,41 hari $(9,84$ jam $)$ dan 0,437 hari (10,48 jam) bulan September dengan rata-rata dalam 4 bulan tersebut adalah 0.429 hari $(10,29$ jam $)$. rata-rata pemenuhan pesanan untuk setiap bulan menunjukkan siklus yang stabil artinya kinerja supply chain dari indicator siklus pemenuhan pesanan dalam kinerja yang baik. Hal ini sesuai dengan penelitian Sari (2015) yang menyatakan indikator siklus pemenuhan pesanan untuk peternakan berada dalam kondisi superior.

\section{Fleksibilitas Supply Chain}

Fleksibilitas ialah waktu yang diperlukan dalam hal respon ketika adanya pesanan tidak terduga baik peningkatan atau penurunan pesanan tanpa penalti. Dalam tabel 2, fleksibilitas supply chain pada periode juni sebesar 8.35 jam $(0.348$ hari) kemudian di bulan juli menjadi 0.5 hari (12 jam), bulan agustus 0.334 hari (4 jam) dan 0.324 hari ( 7.7 jam) untuk bulan September dengan ratarata fleksibilitas dalam 4 bulan tersebut adalah 0.37 hari (8,8 jam). Hal tersebut sesuai dengan kriteria penilaian kinerja menurut Bolstroff dan Rosenbaum (2011), pada indikator siklus pemenuhan pesanan untuk mencapai kriteria baik pada kinerja suatu perusahaan $\leq 10$ hari. artinyaperusahaan mampu memenuhi pesanan tidak terduga dengan waktu yang tidak terlampau lama yaitu kurang dari 24 jam (1 hari). 


\section{- Pengukuran Kinerja Internal}

\section{a. Cash to Cash Cycle Time}

Cash to cash cycle time adalah sebuah matrik pengukuran untuk mengukur kesehatan finansial supply chain. Berdasarkan tabel 2, diketahui nilai rata-rata cash to cash cycle time adalah 7 hari atau kurang dari 20 hari berarti termasuk dalam posisi superior. Hasil tersebut sesuai dengan kriteria penilaian kinerja menurut Bolstroff dan Rosenbaum (2011) artinya kemampuan peternak dalam mengelola aset barang menjadi uang tunai sudah mencapai posisi kinerja terbaik.

Tabel 2. Kinerja Internal dan Kinerja Eksternal Peternak Mitra

\begin{tabular}{|c|c|c|c|c|c|c|c|}
\hline \multirow{2}{*}{ Atribut } & \multirow{2}{*}{ Indikator } & \multirow{2}{*}{$\begin{array}{c}\text { Rata- } \\
\text { rata }\end{array}$} & \multicolumn{5}{|c|}{ Peternak } \\
\hline & & & $\overline{B \ln 6}$ & Bln 7 & Bln 8 & Bln 9 & Kategori \\
\hline \multicolumn{8}{|c|}{ Kinerja Eksternal } \\
\hline \multirow[t]{4}{*}{ Reliabilitas } & Kinerja & 100 & 100 & 100 & 100 & 100 & Superior \\
\hline & Pengiriman(\%) & & & & & & \\
\hline & $\begin{array}{l}\text { Kesesuaian dengan } \\
\text { standar (\%) }\end{array}$ & 91.91 & 90.25 & 92.2 & 92.19 & 93.01 & Advantage \\
\hline & $\begin{array}{l}\text { Pemenuhan pesanan } \\
\text { (\%) }\end{array}$ & 100 & 100 & 100 & 100 & 100 & Superior \\
\hline \multirow[t]{2}{*}{ Responsivitas } & $\begin{array}{l}\text { Siklus pemenuhan } \\
\text { pesanan } \\
\text { (hari) }\end{array}$ & 0.429 & 0.434 & 0.433 & 0.41 & 0.437 & Superior \\
\hline & Lead Time (hari) & 0.679 & 0.684 & 0.683 & 0.660 & 0.687 & Superior \\
\hline Fleksibilitas & $\begin{array}{l}\text { Fleksibilitas supply } \\
\text { chain (hari) }\end{array}$ & 0.377 & 0.348 & 0.5 & 0.334 & 0.324 & Superior \\
\hline \multicolumn{8}{|c|}{ Kinerja Internal } \\
\hline \multirow[t]{2}{*}{ Aset } & Cash to Cash Cycle & 7 & 7 & 7 & 7 & 7 & Superior \\
\hline & Perseduaan Harian & 3 & 3 & 3 & 3 & 3 & Advantage \\
\hline
\end{tabular}

Sumber : Data Primer Diolah (2019)

\section{b. Persediaan Harian}

Persediaan harian merupakan periode waktu yang masih bisa diatur dan dicukupi dengan ketersediaan produk yang ada. Seluruh peternak mitra menjual langsung hasil ternaknya ke PT SUJ setelah proses pemanenan. Berdasarkan tabel 2, peternak mitra melakukan stok atau persediaan ketika dalam satu hari pascapanen masih ada ayam yang belum didistribusikan dengan persediaan harian selama 3 hari.
Dengan kondisi tersebut, indikator persediaan harian mencapai level advantage sesuai dengan kriteria penilaian kinerja menurut Bolstroff dan Rosenbaum (2011) yang menyatakan kalau persediaan diantara 4-13 hari maka masuk dalam kategori advantage atau dapat dikatakan ada sebagian besar hasil panen yang tidak langsung terjual setelah masa panen. Untuk itu, peternak masih melakukan persediaan selama beberapa hari, meskipun jarang 
dilakukan dan secara tidak terencana yang disajikan pad tabel 2 kinerja peternak mitra.

\section{B. Kinerja PT SUJ}

PT SUJ dalam supply chain berperan penting sebagai pembudidaya sekaligus berperan sebagai driven dalam supply chain. Perusahaan menggunakan input yang sebagian besar berasal dari perusahaan sendiri Adapun perbandingan nilai rata-rata kinerja supply chain perusahaan dalam 4 bulan terakhir akan disajikan dalam tabel 3 sebagai berikut :

Tabel 3. Kinerja Internal dan Kinerja Eksternal Perusahaan

\begin{tabular}{|c|c|c|c|c|c|c|c|}
\hline \multirow{2}{*}{ Atribut } & \multirow{2}{*}{ Indikator } & \multirow{2}{*}{ Kondisi } & \multicolumn{5}{|c|}{ Perusahaan } \\
\hline & & & $B \ln 6$ & Bln 7 & $B \ln 8$ & Bln 9 & Kategori \\
\hline \multicolumn{8}{|c|}{ Kinerja Eksternal } \\
\hline \multirow[t]{3}{*}{ Reliabilitas } & $\begin{array}{l}\text { Kinerja pengiriman } \\
(\%)\end{array}$ & 100 & 100 & 100 & 100 & 100 & Superior \\
\hline & $\begin{array}{l}\text { Kesesuaian dengan } \\
\text { standar (\%) }\end{array}$ & 97.14 & 96.499 & 97.148 & 98.21 & 96.7 & Superior \\
\hline & $\begin{array}{l}\text { Pemenuhan } \\
\text { pesanan (\%) }\end{array}$ & 100 & 100 & 100 & 100 & 100 & Superior \\
\hline \multirow[t]{2}{*}{ Responsivitas } & $\begin{array}{l}\text { Siklus pemenuhan } \\
\text { pesanan } \\
\text { (hari) }\end{array}$ & 0.328 & 0.405 & 0.399 & 0.403 & 0.106 & Superior \\
\hline & Lead Time (hari) & 0.538 & 0.615 & 0.609 & 0.6139 & 0.316 & Superior \\
\hline \multirow[t]{2}{*}{ Fleksibilitas } & Fleksibilitas(hari) & 0.3149 & 0.307 & 0.32 & 0.316 & 0.315 & Superior \\
\hline & & Kiner & ja Inter & & & & \\
\hline \multirow[t]{2}{*}{ Aset } & Cash to Cash Cycle & 9 & 9 & 9 & 9 & 9 & Superior \\
\hline & Persediaan Harian & 4 & 4 & 4 & 4 & 4 & Advantage \\
\hline
\end{tabular}

Sumber : Data Primer Diolah (2019)

Dari tabel 3 kinerja rantai pasok perusahaan telah mencapai kinerja yang baik. Hal ini terjadi karena terdapat koordinasi dan kolaborasi yang baik antar divisi dalam manajemen PT SUJ.

\section{Kinerja Eksternal Perusahaan}

\section{Lead Time Pemenuhan Pesanan}

Lead time pesanan adalah indikator yang menjelaskan waktu yang diperlukan oleh perusahaan untuk memenuhi kebutuhan pelanggan. Dalam tabel 3, lead time supply chain pada periode juni sebesar 0,615 hari $(14,76$ jam), bulan juli 0,609 hari (14,78 jam), bulan agustus menjadi 0,6139 hari
(14,73 jam) dan 0,316 hari (7,584 jam) untuk bulan September dengan rata-rata dalam 4 bulan tersebut adalah 0,314 hari (7,536 jam). rata-rata lead time rntai pasok perusahaan untuk setiap bulan menunjukkan siklus yang meningkat.

Jika dilihat peningkatan lead time ini menunjukkan nilai lead time yang didapat semakin kecil dan berada pada posisi superior. Hal ini sejalan dengan penelitian Sari (2015) yang menyatakan lead time untuk ayam broiler berada dalam level superior dan berdasarkan benchmark scorCard artinya perusahaan semakin baik dalam waktu tunggu dalam 
penilaian kinerja supply chainnya. Lead time perusahaan ini cenderung semakin baik dalam setiap periodenya.

\section{Siklus Pemenuhan Pesanan}

Siklus pemenuhan pesanan merupakan siklus waktu yang dibutuhkan oleh perusahaan untuk satu siklus order, yang dinyatakan dalam satuan hari. Dalam tabel 3, siklus pemenuhan pesanan supply chain pada periode juni sebesar 0,405 hari $(9,72$ jam), bulan juli 0,399 hari (9,576 jam) , bulan agustus menjadi 0.403 hari $(9,672$ jam) dan untuk bulan September 0,106 hari (2,54 jam) dengan rata-rata dalam 4 bulan tersebut adalah 0.328 hari $(7,87$ hari) . rata-rata siklus pemenuhan pesanan untuk setiap bulan menunjukkan siklus yang meningkat secara signifikan. Siklus pemenuhan pesanan berada pada posisi superior, artinya pada siklus pemenuhan pesanan sudah mencapai posisi baik. Hal ini juga sesuai dengan kriteria penilaian kinerja menurut Bolstroff dan Rosenbaum (2011), pada indikator siklus pemenuhan pesanan untuk mencapai kriteria baik pada kinerja suatu perusahaan $\leq 4$ hari.

\section{Fleksibilitas}

Fleksibilitas adalah waktu yang dibutuhkan untuk merespon supply chain apabila ada pesanan yang tak terduga baik peningkatan atau penurunan pesanan tanpa terkena biaya penalti, yang dinyatakan dalam satuan hari. Pada Tabel 3, fleksibilitas supply chain pada semester pertama sebesar 4.75 jam (0.20 hari) menjadi 4.78 jam (0.20 hari). Hal ini juga sesuai dengan kriteria penilaian kinerja menurut Bolstroff dan Rosenbaum (2011), pada indikator siklus pemenuhan pesanan untuk mencapai kriteria baik pada kinerja suatu perusahaan $\leq 10$ hari artinya perusahaan mampu memenuhi pesanan tidak terduga dengan waktu yang tidak terlampau lama yaitu kurang dari 24 jam (1 hari).

\section{Kinerja Pengiriman}

Kinerja pengiriman merupakan persentase pengiriman pesanan tepat waktu yang sesuai dengan tanggal pesanan pelanggan yang dinyatakan dalam persen. Hasil pembahasan pada tabel 3 menunjukkan bahwa Kinerja pengiriman yang dilakukan PT SUJ sangat baik dan telah mencapai 100 persen untuk setiap pengiriman. Perbandingan nilai kinerja pengiriman menurut Bolstroff dan Rosenbaum (2011), pada indikator Kinerja pengiriman untuk mencapai kriteria superior pada kinerja suatu perusahaan $\geq 95.00$ persen.

\section{Pemenuhan Pesanan}

Pemenuhan pesanan diukur dari sejauh mana PT SUJ mampu memenuhi pesanan dari pelanggan secara baik. Pada tabel 3, PT SUJ mampu memenuhi pesanan pelanggan dengan sangat baik dengan mencapai pemenuhan pesanan 100 persen. Jika dibandingkan dengan standar penilaian kinerja menurut Bolstroff dan Rosenbaum (2011) nilai pemenuhan pesanan mampu mencapai posisi superior.

\section{Kesesuaian dengan Standar}

Kesesuaian standar adalah persentase jumlah permintaan konsumen yang dikirimkan sesuai dengan standar yang ditentukan konsumen, yang dinyatakan dalam persen. Dalam tabel 3, kesesuaian 
standar pesanan supply chain pada periode juni sebesar $96,499 \%$, bulan juli 92,148 \%, bulan agustus menjadi $98,21 \%$ dan 96,7\% untuk bulan September dengan rata-rata dalam 4 bulan tersebut adalah 97,14\%. rata-rata kesesuain standar pesanan untuk setiap bulan menunjukkan siklus yang stabil. Nilai 97.14 \% juga menunjukkan bahwa kinerja peternak untuk kesesuaian standar produk masih berada dalam posisi superior.

\section{Pengukuran Kinerja Internal}

\section{a. Cash to Cash Cycle Time}

Cash to cash cycle time adalah sebuah matrik pengukuran untuk mengukur kesehatan finansial supply chain. Berdasarkan tabel 3 diatas dapat dilihat bahwa nilai rata-rata cash to cash cycle time adalah 9 hari artinya kurang dari 20 hari yang berarti berada dalam posisi superior. Hasil tersebut sesuai dengan kriteria penilaian kinerja menurut Bolstroff dan Rosenbaum (2011) .

\section{b. Persediaan Harian}

Persediaan harian merupakan periode waktu yang masih bisa diatur dan dicukupi dengan ketersediaan produk yang ada, jika tidak ada pasokan lebih lanjut dan dinyatakan dalam satuan hari. Perusahaan melakukan stok atau persediaan ketika dalam satu hari pascapanen masih ada ayam yang belum didistribusikan atau dapat dikatakan jika terjadi kelebihan panen. Dari tabel 3, dapat dinilai rata-rata kinerja persediaan harian petani adalah 4 hari berarti termasuk dalam posisi advantage. Hal ini juga sesuai dengan kriteria penilaian kinerja menurut Bolstroff dan Rosenbaum (2011), pada indikator siklus pemenuhan pesanan untuk mencapai kriteria advantage pada kinerja suatu perusahaan berada di sekitar 13.00- 0.01 hari.

\section{SIMPULAN}

Pengukuran kinerja supply chain eksternal menunjukkan bahwa peternak sudah memiliki kemampuan dalam melakukan pengiriman pasokan ayam yang tepat waktu dan sesuai dengan standar meskipun masih bisa lebih ditingkatkan lagi untuk mencapai penilaian superior. Sementara untuk indikator internal, peternak telah mampu mencapai persediaan dan dengan baik dengan mencapai level superior untuk cash to cash cycle dan advantage untuk persediaan harian.

Sementara itu, kinerja PT SUJ menunjukkan bahwa perusahaan telah mencapai kemampuan dalam mengorganisir dan mengatur kinerja eksternal dan kinerja eksternal. Dalam kinerja internal, perusahaan telah melakukan pengiriman pasokan ayam yang memenuhi kriteria standar baik dari segi kualitas maupun ketepatan waktu untuk mencapai penilaian superior . Sedangkan untuk kinerja internal, perusahaan telah mencapai level superior untuk cash to cash cycle dan level advantage untuk indikator persediaan harian.

\section{DAFTAR PUSTAKA}

Ahmad NH, Yuliawati E. 2013. Analisa pengukuran dan perbaikan kinerja supply chain ayam di Bandung. Jurnal Teknologi. 6(2): 179-186.

Anggraeni W. 2012. Pengukuran kinerja pengelolaan rantai pasokan pada 
PT Crown closures Indonesia. Jurnal Teknik Industri.

Bolstorff P, Rosenbaum R. 2011. Supply chain Excellence: A Handbook for Dramatic Improvement Using the SCOR Model. New York (US): AMACOM.

Mutakin A, Hubeis M. 2011. Pengukuran kinerja manajemen supply chain. Jurnal Manajemen dan Organisasi. 2(3).

Paul J. 2014. Panduan Penerapan Tranformasi Supply Chain Dengan Metode SCOR pada untuk peternakan. Jakarta (ID): Penerbit PPM.

Sari PN. 2015. Pengaruh Relationship Marketing Terhadap Kinerja Supply chain ayam Broiler Di Kabupaten Bandung Melalui Integrasi [tesis]. Bogor (ID): Institut Pertanian Bogor.
Tsao YC. 2013. Designing a Fresh Food Supply chain Network: An Application of Nonlinear Programming. Journal of Applied Mathematic.

Lockamy A, McCormack K. 2014. Linking SCOR Planning Practices chicken to Supply Chain Performance. International Journal of Operations and Production Management. 24(12):1192-1218.

Mutakin A, Hubeis M. 2011. Pengukuran kinerja manajemen rantai pasok ayam afkir. Jurnal Manajemen dan Organisasi. 2(3).

Saputra H, Fithri P. 2012. Perancangan model pengukuran kinerja green rantai pasok pulp dan kertas. Jurnal Optimasi Sistem Industri. 11(1):193-202. 